\title{
Differential Maternal Feeding Practices, Eating Self- Regulation, and Adiposity in Young Twins
}

AUTHORS: Gina L. Tripicchio, MS, MSEd, ${ }^{a}$ Kathleen L. Keller, PhD, ${ }^{b}$ Cassandra Johnson, MSPH, a Angelo Pietrobelli, MD, ${ }^{c, d}$ Moonseong Heo, PhD, and Myles S. Faith, $\mathrm{PhD}^{\mathrm{a}}$

aDepartment of Nutrition, Gillings School of Global Public Health, The University of North Carolina at Chapel Hill, Chapel Hill, North Carolina; ${ }^{b}$ Departments of Nutritional Sciences and Food Science, The Pennsylvania State University, University Park, Pennsylvania; 'Pediatric Unit, Verona University Medical School, Verona, Italy; aPennington Biomedical Research Center, Baton Rouge,

Louisiana; and ${ }^{D}$ Department of Epidemiology and Population Health, Albert Einstein College of Medicine, Bronx, New York

\section{KEY WORDS}

pediatrics, psychosocial, genetics, adiposity, parenting practices

\section{ABBREVIATIONS}

\%BF-percent body fat

CFQ—Child Feeding Questionnaire

COMPX\% - caloric compensation

DXA—dual energy x-ray absorptiometry

DZ-dizygotic

$\mathrm{MZ}$ - monozygotic

NSE-nonshared environment

Ms Tripicchio carried out the initial analyses and drafted the initial manuscript; Dr Keller conceptualized and designed the study, and collected data; Ms Johnson contributed to the writing of the initial manuscript; Dr Pietrobelli conceptualized and designed the study; Dr Heo conceptualized and designed the study, and reviewed the data analyses; Dr Faith conceptualized and designed the study, collected data, contributed to the initial writing of the manuscript, and reviewed the data analyses; and all authors critically reviewed and revised the manuscript and approved the final manuscript as submitted.

www.pediatrics.org/cgi/doi/10.1542/peds.2013-3828

doi:10.1542/peds.2013-3828

Accepted for publication Aug 5, 2014

Address correspondence to Myles S. Faith, PhD, The University of North Carolina at Chapel Hill, 2211 McGavran-Greenberg Hall, CB7461, Chapel Hill, NC 27599-7461. E-mail: mfaith@unc.edu

PEDIATRICS (ISSN Numbers: Print, 0031-4005; Online, 1098-4275).

Copyright (c) 2014 by the American Academy of Pediatrics

FINANCIAL DISCLOSURE: The authors have indicated they have no financial relationships relevant to this article to disclose.

FUNDING: All phases of this study were supported by National Institutes of Health grant K08MH01530. Funded by the National Institutes of Health (NIH).

POTENTIAL CONFLICT OF INTEREST: The authors have indicated they have no potential conflicts of interest to disclose.
WHAT'S KNOWN ON THIS SUBJECT: Restrictive feeding by parents is associated with poorer eating self-regulation and increased child weight status. However, this association could be due to confounding home environmental or genetic factors that are challenging to control.

WHAT THIS STUDY ADDS: Differential maternal restrictive feeding is associated with differences in twins' caloric compensation and BMI $z$ score. Controlling for the shared home environment and partially for genetics, these findings further support a true (ie, unconfounded) association between restriction and childhood obesity.

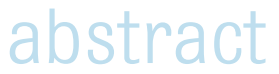

OBJECTIVE: Restrictive feeding is associated with childhood obesity; however, this could be due to other factors that drive children to overeat and parents to restrict (eg, child genetics). Using a twin design to better control for confounders, we tested differences in restrictive feeding within families in relation to differences in twins' self-regulatory eating and weight status.

METHODS: Sixty-four same-gender twin pairs (4-7 years old) were studied with their mothers. Child caloric compensation ability (COMPX\% index) was assessed by using a laboratory-based protocol. The Child Feeding Questionnaire assessed mothers' self-reported feeding styles toward each twin. Child BMI $\left(\mathrm{kg} / \mathrm{m}^{2}\right)$ and $\mathrm{BMI} z$ score were calculated by using measured weight and height; percent body fat and waist circumference were also assessed. Partial correlations examined within-twin pair differences in Child Feeding Questionnaire subscales in relation to within-twin pair differences in anthropometry and caloric compensation (COMPX\%).

RESULTS: Differences in maternal restriction were significantly associated with within-pair differences in child COMPX\% and BMI $z$ score. Mothers reported more restriction toward the heavier and more poorly compensating twin. Additionally, within-pair differences in parental pressure to eat were associated with significant differences in BMI $z$ score, percent body fat, and waist circumference. Mothers were more pressuring toward the lighter twin.

CONCLUSIONS: Mothers vary in their feeding practices, even among same-gender twin pairs, which might influence differences in adiposity. Future research needs to elucidate cause-and-effect and intervention implications regarding parental restriction and pressure-to-eat prompts. Pediatrics 2014;134:e1399-e1404 
One of the major discoveries in the field of child development is that siblings, despite living in the same household, have their own "nonshared" environments (NSEs). ${ }^{1-3}$ NSEs include unique interactions with parents and peers and influence behavioral outcomes, including growth and development. 4,5 NSEs also impact children's adiposity, ${ }^{6-8}$ as well as their dietary patterns, ${ }^{9}$ eating rate, ${ }^{10}$ food preferences, ${ }^{11}$ appetite, ${ }^{12,13}$ and food neophobia. ${ }^{14}$ A challenge, however, has been to identify specific factors in NSEs that drive pediatric obesity. Study designs necessary to discover NSEs typically require biologically related children (eg, siblings, adoptees, twins) who can be compared with respect to unique life exposures, while controlling for shared genetic and environmental factors. Despite this barrier, the study of siblings is a powerful research strategy for identifying environmental determinants of behavior. ${ }^{15,16}$

Might certain parental feeding practices (in particular, restrictive feeding) be an NSE driver of child overconsumption and obesity? Restrictive feeding, or controlling children's access to and intake of certain foods, is associated with child overeating and obesity, ${ }^{17,18}$ and might disrupt children's ability to self-regulate food intake. ${ }^{19}$ Restriction may also interact with poorer self-control to exacerbate excess weight gain in children. ${ }^{20}$ However, few family studies have addressed this question and most study designs are limited to the use of sibling pairs. Payne et al ${ }^{21}$ reported that differential restrictive feeding toward siblings was related to differential levels of concern about child weight rather than objective differences in weight. Farrow et al22 reported that, within families, mothers were more restrictive toward children who reportedly were fussier and had a greater desire to drink beverages compared with their siblings. On the other hand, Saelens et a ${ }^{23}$ reported no differences in maternal control between obese and nonobese siblings who were 7 to 12 years old. Other parental feeding practices of interest include pressure to eat, characterized by parental force to consume food, and monitoring, or oversight of child eating behavior by parents.

The main purpose of this study was to test whether mothers' differential restrictive feeding was associated with differences in children's self-regulatory eating, specifically, caloric compensation ability (COMPX\%, defined below) and weight status, within same-gender twins (4-7 years). We hypothesized that differential restrictive feeding would be associated with differences in children's COMPX\% and weight status. Specifically, we predicted that greater maternal restrictive feeding toward one twin, relative to his or her cotwin, would be associated with poorer self-regulatory eating behavior (favoring overconsumption) and higher BMI $z$ scores for the restricted twin. To fully characterize parent-feeding practices and understand their associations with child eating behavior and weight status, we also examined withinfamily differences in the 2 other feeding practices assessed by the Child Feeding Questionnaire (CFQ): pressure to eat and monitoring. As with restriction, we examined whether within-family differences in these traits were associated with differential child weight status and COMPX\%. Previous research has linked pressure to eat prompts with reduced child weight status, ${ }^{24,25}$ but associations with monitoring generally have not been found.

\section{METHODS}

\section{Sample}

A total of 69 same-gender twin pairs participated in Project Grow-2-Gether, 26,27 including 40 monozygotic (MZ) and 29 dizygotic (DZ) pairs. Participants were recruited through twins' clubs, Twins Magazine, general newspaper advertisements, targeted mailings, and word-of-mouth.
Participants were compensated $\$ 175$ for participation in appreciation of their time and travel. Children 4 to 7 years old and their mothers visited the New York Obesity Research Center, St Luke'sRoosevelt Hospital, for 4 assessments over 2 weeks. Visits were 1 to 2 weeks apart and each visit lasted $\sim 60$ to 75 minutes. The energy compensation protocol was performed on the first 2 visits and body composition assessments were collected on the third or fourth visit. On the third and fourth visits, we video-recorded mother-child interactions during structured laboratory lunch meals to objectively assess feeding dynamics. Mothers ate separately with each twin during these visits, which was replicated across visits 3 and 4 to evaluate reliability. Further details of these procedures are provided elsewhere. ${ }^{14,26}$

For the present report, we examined 64 twin pairs (39 MZ, 25 DZ pairs) who had complete data for the compensation protocol, the CFQ, and child weight and height measures. Twin assignment within families (eg, twin 1 vs 2) was randomly designated before the first assessments occurred. Parental consent was obtained at the beginning of the first visit, and the study received full approval from the institutional review board of St Luke'sRoosevelt Hospital.

\section{Measures}

\section{Self-Regulatory Eating}

We used an established preloading paradigm ${ }^{28,29}$ to assess children's caloric compensation. In brief, parents were instructed not to feed their children any meals or snacks for at least 2 hours before their visit. We did not assess children's full dietary intake for the morning of or 24 hours before the visit because of concerns of participant burden. During the first 2 laboratory visits, children were randomly assigned to receive cherryflavored carbohydrate drink preloads (173 g) on arrival that were either low 
calorie (3 kcal) or high calorie (159 kcal). Whichever treatment (eg, lowcalorie or high-calorie preload) was assigned on the first visit was reversed on the second visit. After drinking the preload, the twins were given a 25minute play period. Preloads were weighed during the play period to calculate consumption. After the play period, twins were served a multi-item lunch; they could eat as much as they wanted and were able to request additional servings. Food items included macaroni and cheese (133 g), canned string beans (57 g), string cheese (30 g), graham crackers (25 g), green grapes (113 g), baby carrots (35 g), and whole milk $(513 \mathrm{~g})$. The total caloric value of all the food items and milk, collectively, was approximately $935 \mathrm{kcal}$. Meal intake following each preload (high and low) was calculated for each twin and used to determine compensation ability.

Compensation ability was operationalized as the percentage compensation index (COMPX\%):

$$
\operatorname{COMPX}(\%)=\frac{\text { Meal }_{\text {low }}-\text { Meal }_{\text {high }}}{\text { Preload high }_{\text {Preload }} \text { low }}(100),
$$

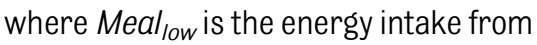
the lunch meal after the low-energy preload, Meal high is the energy intake from the lunch meal after the highenergy preload, Preload $_{\text {high }}$ is the energy consumed from the high-energy preload intake (ie, $159 \mathrm{kcal}$, assuming the entire drink was consumed), and Preload $_{\text {low }}$ is the energy consumed from the low-energy preload intake (ie, $3 \mathrm{kcal}$ assuming the entire drink was consumed). Better compensation indicates the ability to adjust caloric intake in a meal relative to the calories in the preload. Specifically, COMPX\% is a continuous measure scaled such that $100 \%$ reflects "perfect" compensation. This is achieved when the difference in the child's lunch intake over the 2 sessions is equal to the difference in the amount of energy between the 2 respective preloads consumed (high and low).
To illustrate this formula, consider a child who consumes exactly $456 \mathrm{kcal}$ at lunch after the low-energy preload and $300 \mathrm{kcal}$ at lunch after the highenergy preload. Plugging these values into the formula yields ([456 - 300]/ $[159-3])^{*} 100$, or $\mathrm{COMPX} \%=100 \%$. Had this child consumed $800 \mathrm{kcal}$ rather than $300 \mathrm{kcal}$ after the high-energy preload (with all else the same), this would have yielded $([456-800] /[159-3]) * 100$, or $\mathrm{COMPX \%}=-220.51 \%$. But had this child consumed only $150 \mathrm{kcal}$ after the high-energy preload (with all else the same), this would have yielded $([456-150] /[159-3]) * 100$, or COMPX\% $=$ $196.15 \%$. Thus, $100 \%$ is perfect compensation, with progressively lower, negative scores reflecting the tendency to overeat after the high-energy preload relative to the low-energy preload ("undercompensation"). Progressively higher scores reflect the tendency to undereat after the high-energy relative to the low-energy preload ("overcompensation"). Undercompensation, leading to overconsumption, has been associated with overweight status. ${ }^{28}$

\section{Parental Feeding Practices}

The $\mathrm{CFQ}^{30}$ was administered to mothers to assess self-reported feeding practices (eg, restriction, pressure to eat, and monitoring). Restriction indicates the extent to which parents limit their child's access to foods, pressure to eat assesses parents' propensity to try to force their children to consume more food, and monitoring is used to determine the degree to which parents oversee their child's eating.

\section{Anthropometry}

Each child's height and weight were measured and converted to weight and adiposity indexes. BMI, BMl $z$ scores, and percentiles were calculated by using appropriate age- and gender-specific cutoffs for height and weight. ${ }^{31}$ Each child's waist circumference was measured and dual energy x-ray absorptiometry (DXA) 32 was used to assess percent body fat (\%BF). Of the 128 children (from the 64 families) analyzed in this report, only 105 had waist circumference measures and 95 had DXA measures.

\section{Data Analytic Plan}

Descriptive statistics are presented as means and SDs. To test our hypotheses, differences between each twin pair were calculated to create a within-pair difference score for each variable. Differential parental practices also were calculated to create a differential parent score within each twin pair. Partial correlations (adjusting for child gender and zygosity; eg, MZ or DZ) tested whether within-family differences in CFQ subscales were associated with within-family differences in child anthropometric measures and COMPX $\%$. All statistics were analyzed by using SPSS (version 22; IBM SPSS Statistics, IBM Corporation, Chicago, IL).

\section{RESULTS}

Descriptive statistics are presented for each twin (Table 1). The mean child age was 58.4 (17.7) months and the race/ethnicity breakdown was $52 \%$ white, 17\% African American, 15\% Hispanic, $3 \%$ Asian, and $13 \%$ other or mixed background. Most mothers were college educated or higher (59\%), married (75\%), and currently employed (58\%).

Pearson correlation coefficients represent the associations between withinpair differences in maternal feeding practices and within-pair differences in child adiposity and self-regulatory eating measures (Table 2). Within-pair differences in restrictive feeding were associated with within-pair differences in BMl $z$ score $(r=0.31, P=.014)$. As predicted, mothers reported being more restrictive toward their relatively heavier twin compared with the lighter cotwin. Additionally, the within-pair difference in self-reported pressure to eat was negatively associated with within-pair 
TABLE 1 Descriptive Statistics for Child Age, Child Anthropometric Measures, and Parental Feeding Practices, Presented by Twin Number

\begin{tabular}{lccc}
\hline & Twin 1 Mean (SD) & Twin 2 Mean (SD) & Mean Differential Score (SD) \\
\hline Age, mo & $58.37(17.67)$ & $58.37(17.67)$ & N/A \\
Height, m & $1.07(0.10)$ & $1.06(0.11)$ & $0.00(0.03)$ \\
Weight, kg & $18.30(4.05)$ & $18.66(5.84)$ & $-0.37(4.09)$ \\
COMPX\% & $101.01(120.44)$ & $76.57(121.82)$ & $24.43(148.75)$ \\
CFQ-Restriction & $2.83(0.80)$ & $2.89(0.83)$ & $-0.06(0.68)$ \\
CFQ-Pressure to Eat & $2.69(1.03)$ & $2.68(1.08)$ & $0.01(0.98)$ \\
CFQ-Monitoring & $3.64(1.08)$ & $3.43(1.15)$ & $0.21(0.62)$ \\
BMl, kg/m & $15.85(1.48)$ & $16.02(2.42)$ & $-0.18(2.34)$ \\
BMl z score & $0.11(1.07)$ & $0.11(0.94)$ & $0.001(0.92)$ \\
BMI\% & $53.97(28.07)$ & $52.88(26.42)$ & $1.09(23.81)$ \\
\%BF & $15.36(5.31)$ & $14.91(6.09)$ & $0.40(5.42)$ \\
Waist circumference, cm & $51.85(4.14)$ & $52.33(7.30)$ & $-0.12(1.10)$ \\
\hline
\end{tabular}

Data presented are means ( \pm SDs) for each of the variables. Anthropometric measures were obtained in a body composition laboratory and feeding measures were obtained from the CFQ.30 The means for twins 1 and 2 did not significantly differ for any of the measures $(P>.05) ; n=64$ families (128 children) for measures of child age, height, weight, COMPX\%, CFQRestriction, CFQ-Pressure to Eat, CFQ-Monitoring, BMI, BMI $z$ score, and BMI\%; $n=47$ families (94 children) for measures of child \%BF; $n=50$ families (100 children) for measures of child waist circumference. BMI\%, BMI percentile; N/A, not applicable differences in BMl z score $(r=-0.40, P=$ $.001)$, \%BF ( $r=-0.38, P=.009)$, and waist circumference $(r=-0.40, P=.004)$. Mothers encouraged greater food intake by the lighter twin relative to the heavier cotwin. There were no significant associations for monitoring.

Compensation ability (COMPX\%) was negatively associated with parental restriction ( $r=-0.27, P=.034)$, as predicted. Mothers were more restrictive toward the twin showing poorer compensation (favoring overconsumption) relative to the cotwin showing better compensation. No other significant associations were shown for compensation $(P>.05)$.

\section{DISCUSSION}

We found that mothers differed in their feeding practices toward children, even though they were same-gender twin pairs, and these differences related to child weight status. Mothers reported more restrictive feeding practices toward their heavier compared with their lighter twin; additionally, mothers were more restrictive toward the twin with poorer compensation favoring overconsumption. The long-term outcomes of restriction and compensation ability cannot be assessed in this study, although other studies have linked poorer compensation to increased weight status over time ${ }^{20,33}$ Additionally, our findings align with a related body of literature on self-regulation and childhood obesity. Specifically, poorer self-control and delay of gratification in early childhood are associated with a higher weight status or greater weight gain later in life. ${ }^{34-38}$ Future research should examine whether restrictive feeding
TABLE 2 Pearson Correlation Coefficients Representing the Associations Between Within TwinPair Differences in Maternal Feeding Practices and Within Twin-Pair Differences in Child Adiposity and Self-Regulatory Eating Measures

\begin{tabular}{lccc}
\hline & $\Delta$ Restriction & $\Delta$ Pressure to Eat & $\Delta$ Monitoring \\
\hline$\Delta$ COMPX\% & $-0.27^{\star}$ & -0.04 & -0.20 \\
$\Delta \mathrm{BMI}, \mathrm{kg} / \mathrm{m}^{2}$ & 0.16 & $-0.42^{\star \star}$ & -0.09 \\
$\Delta \mathrm{BMl} z$ score & $0.31^{\star}$ & $-0.40^{\star \star}$ & -0.06 \\
$\Delta$ \%BF & 0.23 & $-0.38^{\star}$ & 0.08 \\
$\Delta$ Waist circumference, cm & 0.05 & $-0.40^{\star}$ & -0.08 \\
\hline
\end{tabular}

Weight and height measures were assessed in a body composition laboratory. Parental feeding practices were assessed by the Child Feeding Questionnaire. ${ }^{30} \Delta$ refers to the difference score (ie, twin 1 minus twin 2) within twin pairs for each respective measure. $n=64$ families (128 children) for measures of COMPX\%, BMI, and BMI $z$ score; $n=47$ families (94 children) for measures of child body fat; $n=50$ families (100 children) for measures of child waist circumference; $n=64$ families (128 children) for measures of CFQ-Restriction, CFQ-Pressure to Eat, and CFQ-Monitoring. ${ }^{\star} P<.05$; ${ }^{* \star} P \leq .001$. impedes children's delay of gratification and impulsivity.

We also found that differential pressure to eat within families was associated with differences in twins' adiposity. Specifically, the children receiving increased pressure to eat had a lower $\mathrm{BMI}, \mathrm{BMI} z$ score, \%BF, and waist circumference compared with their cotwins. Previous studies have shown this association between pressure to eat and lower child weight status across families, ${ }^{39,40}$ and experimental studies have found that pressuring children to eat (eg, "Finish your soup, please") can have counterproductive effects on a child's eating and food preferences. ${ }^{41}$ Pressuring a child to eat beyond satiety might also contribute to excess weight gain. ${ }^{42}$ Interestingly, unlike restriction, differential pressure to eat was not related to differential caloric compensation in our sample, suggesting an alternative mechanism other than disrupted eating regulation.

Our findings should be considered in light of study limitations. First, as this was cross-sectional research, the causal direction of associations cannot be determined. Second, as we used samegender twin pairs, we could not test for gender differences in feeding practices within families. The use of oppositegender DZ twin pairs could be a powerful strategy for addressing this question. Third, we did not explore other feeding styles that have been examined in the literature, such as indulgent feeding, which have been linked to obesity in lower-income families. ${ }^{43-46}$ Finally, this study was conducted in a laboratory setting and drawing conclusions to eating behavior in the home setting should be done conservatively.

One of the strengths of this study was the use of same-gender twins to control for a shared home environment, which is perfectly correlated among $\mathrm{MZ}$ and DZ twin pairs. The design also partially controls for genes, as MZ twin pairs are 
genetically identical and DZ twin pairs share $50 \%$ of their genetic variation on average. This provides stronger evidence for true (eg, unconfounded, populationlevel) associations among the CFQ subscales, anthropometrics, and COMPX\%. Another study strength was that children's body composition assessment included DXA and waist circumference.

Pediatric obesity treatment and prevention studies are increasingly focusing on feeding practices as intervention targets. ${ }^{47}$ In a family-based obesity treatment study, decreases in child weight status were associated with decreases in parental concern and parental restriction. 48

\section{REFERENCES}

1. Plomin R, Daniels D. Why are children in the same family so different from one another? Int J Epidemiol. 2011;40(3):563-582

2. Plomin R. Commentary: Why are children in the same family so different? Non-shared environment three decades later. Int $J$ Epidemiol. 2011;40(3):582-592

3. Dunn J, Plomin R. Why are siblings so different? The significance of differences in sibling experiences within the family. Fam Process. 1991;30(3):271-283

4. Grilo CM, Pogue-Geile MF. The nature of environmental influences on weight and obesity: a behavior genetic analysis. Psychol Bull. 1991;110(3):520-537

5. Kral TV, Faith MS. Child eating patterns and weight regulation: a developmental behaviour genetics framework. Acta Paediatr Suppl. 2007;96(454):29-34

6. Llewellyn $\mathrm{CH}$, Trzaskowski M, Plomin R, Wardle J. Finding the missing heritability in pediatric obesity: the contribution of genome-wide complex trait analysis. Int $\mathrm{J}$ Obes (Lond). 2013;37(11):1506-1509

7. Haworth CM, Plomin R, Carnell S, Wardle J. Childhood obesity: genetic and environmental overlap with normal-range BMI. Obesity (Silver Spring). 2008;16(7):1585-1590

8. Wardle J, Carnell S, Haworth CM, Plomin R. Evidence for a strong genetic influence on childhood adiposity despite the force of the obesogenic environment. Am J Clin Nutr. 2008;87(2):398-404

9. Faith MS, Rhea SA, Corley RP, Hewitt JK. Genetic and shared environmental influences on children's $24-\mathrm{h}$ food and beverage intake: sex differences at age 7 y. Am J Clin Nutr. 2008;87 (4):903-911
More recently, a family-based intervention targeting "division of responsibility" feeding decreased parental pressure-to-eat prompts and restriction (girls only) in parents of children at risk for obesity. ${ }^{49}$ More controlled trials are needed to evaluate how changes in restrictive feeding impact child eating and weight control. Additionally, parents should be cautious about overly restrictive feeding practices that might disrupt children's selfregulation. Instead, parents might use covert rather than overt control strategies to limit access to energy-dense foods at home..$^{50}$

10. Llewellyn $\mathrm{CH}$, van Jaarsveld $\mathrm{CH}$, Boniface $\mathrm{D}$, Carnell S, Wardle J. Eating rate is a heritable phenotype related to weight in children. $A m \mathrm{~J}$ Clin Nutr. 2008;88(6):1560-1566

11. Hill C, Llewellyn CH, Saxton J, et al. Adiposity and 'eating in the absence of hunger' in children. Int J Obes (Lond). 2008;32(10): 1499-1505

12. Llewellyn $\mathrm{CH}$, van Jaarsveld $\mathrm{CH}$, Plomin $\mathrm{R}$, Fisher A, Wardle J. Inherited behavioral susceptibility to adiposity in infancy: a multivariate genetic analysis of appetite and weight in the Gemini birth cohort. Am J Clin Nutr. 2012;95(3):633-639

13. Carnell S, Haworth CM, Plomin R, Wardle J. Genetic influence on appetite in children. Int J Obes (Lond). 2008;32(10):1468-1473

14. Faith MS, Heo M, Keller KL, Pietrobelli A. Child food neophobia is heritable, associated with less compliant eating, and moderates familial resemblance for BMl. Obesity (Silver Spring). 2013;21(8):1650-1655

15. D’Onofrio BM, Lahey BB, Turkheimer E, Lichtenstein P. Critical need for familybased, quasi-experimental designs in integrating genetic and social science research. $A m \mathrm{~J}$ Public Health. 2013;103(suppl 1):S46-S55

16. Lahey BB, D'Onofrio BM. All in the family: comparing siblings to test causal hypotheses regarding environmental influences on behavior. Curr Dir Psychol Sci. 2010;19(5):319-323

17. Faith MS, Scanlon KS, Birch LL, Francis LA, Sherry B. Parent-child feeding strategies and their relationships to child eating and weight status. Obes Res. 2004;12(11):1711-1722

18. Ventura AK, Birch LL. Does parenting affect children's eating and weight status? Int J Behav Nutr Phys Act. 2008;5:15

\section{CONCLUSIONS}

Even mothers of twins differentially encourage and restrict their children's eating behaviors. Differential restrictive parenting was associated with differences in twins' caloric compensation ability and BMI $z$ score. Mothers also differentially pressured twins to eat, which was inversely associated with differences in twins' adiposity. Feeding practices may be part of the NSEs contributing to pediatric obesity. These relationships should be further explored to establish directionality and to guide intervention development. 49

19. Francis LA, Susman EJ. Self-regulation and rapid weight gain in children from age 3 to 12 years. Arch Pediatr Adolesc Med. 2009 163(4):297-302

20. Anzman SL, Birch LL. Low inhibitory control and restrictive feeding practices predict weight outcomes. J Pediatr. 2009;155(5):651-656

21. Payne LO, Galloway AT, Webb RM. Parental use of differential restrictive feeding practices with siblings. Int J Pediatr Obes. 2011; 6(2-2):e540-e546

22. Farrow CV, Galloway AT, Fraser K. Sibling eating behaviours and differential child feeding practices reported by parents. Appetite. 2009;52(2):307-312

23. Saelens BE, Ernst MM, Epstein LH. Maternal child feeding practices and obesity: a discordant sibling analysis. Int $J$ Eat Disord. 2000;27 (4):459-463

24. Keller KL, Pietrobelli A, Johnson SL, Faith MS. Maternal restriction of children's eating and encouragements to eat as the 'nonshared environment': a pilot study using the child feeding questionnaire. Int J Obes (Lond). 2006;30(11):1670-1675

25. Clark HR, Goyder E, Bissell P, Blank L, Peters J. How do parents' child-feeding behaviours influence child weight? Implications for childhood obesity policy. J Public Health (Oxf). 2007;29(2):132-141

26. Faith MS, Pietrobelli A, Heo M, et al. A twin study of self-regulatory eating in early childhood: estimates of genetic and environmental influence, and measurement considerations. Int J Obes (Lond). 2012;36 (7):931-937

27. Faith MS, Keller KL, Matz $P$, et al. Project Grow-2-Gether: a study of the genetic and 
environmental influences on child eating and obesity. Twin Res. 2002;5(5):472-475

28. Johnson SL, Birch LL. Parents' and children's adiposity and eating style. Pediatrics. 1994;94(5):653-661

29. Birch LL, McPhee LS, Bryant JL, Johnson SL. Children's lunch intake: effects of midmorning snacks varying in energy density and fat content. Appetite. 1993;20(2):83-94

30. Birch LL, Fisher J0, Grimm-Thomas K, Markey CN, Sawyer R, Johnson SL. Confirmatory factor analysis of the Child Feeding Questionnaire: a measure of parental attitudes, beliefs and practices about child feeding and obesity proneness. Appetite. 2001;36(3):201-210

31. Ogden CL, Kuczmarski RJ, Flegal KM, et al. Centers for Disease Control and Prevention 2000 growth charts for the United States: improvements to the 1977 National Center for Health Statistics version. Pediatrics. 2002;109(1):45-60

32. Pietrobelli A, Faith MS, Allison DB, Gallagher D, Chiumello G, Heymsfield SB. Body mass index as a measure of adiposity among children and adolescents: a validation study. J Pediatr. 1998;132(2):204-210

33. Birch LL, Fisher J0, Davison KK. Learning to overeat: maternal use of restrictive feeding practices promotes girls' eating in the absence of hunger. Am J Clin Nutr. 2003;78(2):215-220

34. Duckworth AL, Tsukayama E, Geier AB. Selfcontrolled children stay leaner in the transition to adolescence. Appetite. 2010;54 (2):304-308

35. Schlam TR, Wilson NL, Shoda Y, Mischel W, Ayduk 0. Preschoolers' delay of gratification predicts their body mass 30 years later. $J$ Pediatr. 2013;162(1):90-93
36. Seeyave DM, Coleman S, Appugliese D, et al. Ability to delay gratification at age 4 years and risk of overweight at age 11 years. Arch Pediatr Adolesc Med. 2009;163(4):303-308

37. Graziano PA, Calkins SD, Keane SP. Toddler self-regulation skills predict risk for pediatric obesity. Int J Obes (Lond). 2010;34(4):633-641

38. Tsukayama E, Toomey SL, Faith MS, Duckworth AL. Self-control as a protective factor against overweight status in the transition from childhood to adolescence. Arch Pediatr Adolesc Med. 2010;164(7):631-635

39. Webber L, Cooke L, Hill C, Wardle J. Associations between children's appetitive traits and maternal feeding practices. J Am Diet Assoc. 2010;110(11):1718-1722

40. Webber L, Hill C, Cooke L, Carnell S, Wardle J. Associations between child weight and maternal feeding styles are mediated by maternal perceptions and concerns. Eur $J$ Clin Nutr. 2010;64(3):259-265

41. Galloway AT, Fiorito LM, Francis LA, Birch LL. 'Finish your soup': counterproductive effects of pressuring children to eat on intake and affect. Appetite. 2006;46(3):318-323

42. Faith MS, Heo M, Kral TV, Sherry B. Compliant eating of maternally prompted food predicts increased body mass index z-score gain in girls: results from a populationbased sample. Child Obes. 2013;9(5):427-436

43. Hennessy E, Hughes S0, Goldberg JP, Hyatt RR, Economos CD. Parent behavior and child weight status among a diverse group of underserved rural families. Appetite. 2010;54(2):369-377

44. Hughes S0, Power TG, Orlet Fisher J, Mueller S, Nicklas TA. Revisiting a neglected construct: parenting styles in a child-feeding context. Appetite. 2005;44(1):83-92
45. Hughes S0, Power TG, Papaioannou MA, et al. Emotional climate, feeding practices, and feeding styles: an observational analysis of the dinner meal in Head Start families. Int J Behav Nutr Phys Act. 2011;8:60

46. Hughes S0, Shewchuk RM, Baskin ML, Nicklas TA, Qu H. Indulgent feeding style and children's weight status in preschool. $J$ Dev Behav Pediatr. 2008;29(5):403-410

47. Faith MS, Van Horn L, Appel LJ, et al; American Heart Association Nutrition and Obesity Committees of the Council on Nutrition; Physical Activity and Metabolism; Council on Clinical Cardiology; Council on Cardiovascular Disease in the Young; Council on Cardiovascular Nursing; Council on Epidemiology and Prevention, and Council on the Kidney in Cardiovascular Disease. Evaluating parents and adult caregivers as "agents of change" for treating obese children: evidence for parent behavior change strategies and research gaps: a scientific statement from the American Heart Association. Circulation. 2012;125(9): 1186-1207

48. Epstein LH, Paluch RA, Beecher MD, Roemmich JN. Increasing healthy eating vs. reducing high energy-dense foods to treat pediatric obesity. Obesity (Silver Spring). 2008;16(2): 318-326

49. Agras WS, Hammer LD, Huffman LC, Mascola A, Bryson SW, Danaher C. Improving healthy eating in families with a toddler at risk for overweight: a cluster randomized controlled trial. J Dev Behav Pediatr. 2012;33(7):529-534

50. Ogden J, Reynolds R, Smith A. Expanding the concept of parental control: a role for overt and covert control in children's snacking behaviour? Appetite. 2006;47(1): 100-106 